\title{
A meta-analysis of plant facilitation in coastal dune systems: responses, regions, and research gaps
}

Camila Castanho, Christopher J. Lortie, Benjamin F Zaitchik, Paulo Inácio Prado

Empirical studies in salt marshes, arid, and alpine systems support the hypothesis that facilitation between plants is an important ecological process in severe or 'stressful' environments. Coastal dunes are both abiotically stressful and frequently disturbed systems. Facilitation has been documented, but the evidence to date has not been synthesized. We did a systematic review with meta-analysis to highlight general research gaps in the study of plant interactions in coastal dunes and examine if regional and local factors influence the magnitude of facilitation in these systems. The 32 studies included in the systematic review were done in coastal dunes located in 13 countries around the world but the majority was in the temperate zone (63\%). Most of the studies adopt only an observational approach to make inferences about facilitative interactions whereas only $28 \%$ of the studies used both observational and experimental approaches. Among the factors we tested, only geographic region mediates the occurrence of facilitation more broadly in coastal dune systems. The presence of a neighbor positively influenced growth and survival in the tropics whereas in temperate and subartic regions the effect was neutral for both response variables. We found no evidence that climatic and local factors, such as life-form and life stage of interacting plants affect the magnitude of facilitation in coastal dunes. Overall, conclusions about plant facilitation in coastal dunes depend on the response variable measured, and more broadly, on the geographic region examined. However, the high variability and the limited number of studies, especially in tropical region, indicate we need to be cautious in the generalization of the conclusions. Anyway, coastal dunes provide an important means to explore topical issues in facilitation research including context dependency, local versus regional drivers of community structure, and the importance of gradients in shaping the outcome of net interactions. 
2 Camila de Toledo Castanho $^{14^{*}}$, Christopher J. Lortie ${ }^{2}$,Benjamin Zaitchik ${ }^{3}$ \& Paulo Inácio Prado ${ }^{1}$ 3

4 1. Departamento de Ecologia, Instituto de Biociências, Universidade de São Paulo, São Paulo, São 5 Paulo, Brazil;

6 2. Department of Biology, York University, Toronto, Ontario, Canada;

7 3. Department of Earth and Planetary Sciences, Johns Hopkins University, Baltimore, Maryland, USA;

8 4. Current address: Departamento de Ciências Biológicas, Universidade Federal de São Paulo,

9 Diadema, São Paulo, Brazil

10 *Corresponding author. Universidade Federal de São Paulo, Rua Prof. Artur Riedel, 275, 09972-270,

11 Diadema, SP, Brazil. E-mail: ctcastanho@gmail.com; Tel and Fax: 05511 4043-6428 


\section{Introduction}

14 The role of positive interactions, or facilitation, between plants as key drivers of plant community

15 dynamics and structure is widely recognized and reviewed (Brooker et al., 2008; McIntire \& Fajardo

16 2014). Most empirical studies show that facilitative effects are more important in severe environments

17 because neighbors frequently buffer other individuals from abiotic stressors (He, Bertness \& Altieri,

18 2013). The classical systems that generated this research topic are deserts (Franco \& Nobel, 1989;

19 Flores \& Jurado, 2003), salt marshes (Bertness \& Hacker, 1994; Bertness \& Leonard, 1997), and more

20 recently, alpine systems (Badano et al., 2006; Cavieres et al., 2014). However, positive interactions

21 may also be important in many other ecosystems, and there are similar gradients that likely shift the

22 relative frequency of positive interactions.

23 Recent research in coastal dune vegetation has increasingly focused on facilitation between

24 plants. Coastal dune vegetation, here defined as a mosaic of plant communities in the coast that occupy

25 sandy plains formed by marine deposits (modified from Scarano 2002), is both stressful and highly

26 disturbed, with soil moisture and nutrient limitations, wind exposure, sand burial, salt spray and soil

27 salinity, potentially negatively impacting plants (Wilson \& Sykes, 1999). Similar to desert systems, the

28 presence of some plants, such as shrubs, ameliorate some of these limiting factors and can provide an

29 opportunity for association by other species (Martínez \& García-Franco 2004). Several studies in

30 coastal dunes have shown that the performance of plants established in the neighborhood of other

31 plants are higher than in open areas (Shumway, 2000; Martínez, 2003; Forey et al., 2009; Castanho \&

32 Prado, 2014). However, the occurrence and intensity of facilitation in coastal dunes is also highly

33 variable within and between the studies (Forey et al., 2009; Castanho, Oliveira \& Prado, 2012) thereby

34 suggesting that facilitation is dependent on the local environmental conditions or the gradients (He,

35 Bertness \& Altieri, 2013) and also on the traits of interacting plants (Soliveres et al., 2014). As

36 demonstrated in dunes and other systems, the magnitude of facilitation depends on plant life-stage 
37 (Miriti, 2006; Armas \& Pugnaire, 2009) and plant life-form (Gómez-Aparicio, 2009; Castanho,

38 Oliveira \& Prado, 2012) with higher intensities associated with adult woody benefactors and woody

39 beneficiary species at relatively earlier life-stages. Furthermore, the enviromental severity also shapes

40 the outcome of interactions with more intense facilitation commonly detected under increasingly harsh

41 conditions (He, Bertness \& Altieri, 2013). Consequently, coastal dunes may also be an ideal system to

42 explore net interactions in plants communities, but without synthesis, the context dependency of these

43 positive interactions is not broadly accessible (Gómez-Aparicio, 2009) and research gaps are not easily

44 identified.

Hence, a formal quantitative analysis of the literature in these systems is required. Such analysis

can provide an estimate of the general influence of facilitation on the organization and dynamics of the coastal dunes, further the scope of hypothesis testing in this ecological subdiscipline, and contrast the relative importance of local versus regional drivers of plant community structure (Thebault et al., 2014). We note that the scale of drivers of community structure is an important contemporary issue in ecology (Powers et al., 2009; O'Halloran et al., 2013) that most likely needs to be resolved on an

51 ecosystem-by-ecosystem basis. Moreover, the restoration of degraded coastal dunes is a pressing issue in many regions of the world (Lithgow et al., 2013), and facilitation by dominant coastal plant species

53 is an obvious potential management solution.

To meet these research needs, we present a systematic review and meta-analysis of facilitation

55 in coastal dune plant communities. The systematic review synthesizes current literature and highlights

56 research gaps, while the meta-analysis tests if factors at distinct scales (local versus regional) such as

57 environmental severity, life-form, or life-stage of the interacting plants significantly explained the 58 variation in the intensity of plant facilitation in coastal dunes. 


\section{Data collection}

62 We conducted a survey of the published studies that explicitly tested for the presence of facilitation

63 between plants in coastal dunes. The literature was queried by using ISI Web of Science in June 2013

64 by using a combination of three groups of terms: i) "dune*" or "restinga" or "coastal sand vegetation",

65 and ii) "facilitation" or "positive interaction*" and iii) "plant*" or "tree*" or "shrub*" or "herb*". We

66 did not include competition studies because our main aim was to test factors that affect the intensity of

67 facilitation in dunes and not to make inferences about the importance of facilitation relative to

68 competition. The search led to 90 publications that were subsequently examined firstly for their

69 suitability in the review and secondly in the meta-analysis. For the first selection criterion, only studies

70 that explicitly examined facilitation between plants in coastal dune vegetation under field conditions

71 were included $(n=32)$. Reviews, studies on non-coastal dunes, and those in which at least one of the

72 interacting organisms were not a plant were excluded. To conduct the meta-analysis, the studies also

73 had to include the following: i) data reported in a usable form; and ii) the effect of neighbors on target

74 species compared to the performance of plants without neighbors. When the required data were only

75 reported in graphical form, the graphics were scanned and extracted in table format using TechDig

76 software (Jones, 1998). Multiple outcomes per publication that tested different combinations of

77 neighbor-target species, different life stages, or different sites were treated as independent outcomes.

78 However, if repeated measures were taken from the same experiment, only the results reported at the

79 completion of the experiment were used. Similarly, only the final year in multi-year experiments was

80 used as a conservative estimate of impacts and to avoid pseudoreplication issues. Furthermore, if

81 additional treatment such as water or fertility addition was performed, we only used the estimates from

82 the control level (no addition) because it better approximates the natural/ambient conditions. Authors

83 of publications with unreported datasets were also contacted to secure data. 
To understand how facilitation intensity varies among study outcomes, each outcome was

85 classified according to the following explanatory variables: neighbour and target life-forms, target life

86 stage, geographic regions and environmental severity. Regarding life-forms, neighbour and target

87 plants from each outcome was classified as tree, shrubs or herbs (which was further subdivided into

88 grass and forb when the information was available). For target life stage we classified the target plants

89 as seed, young (including seedlings, saplings and juveniles) or adult. We also classified each outcome

90 according to the geographic region, i.e., as tropical (from latitude $0^{\circ}$ to $\left.28^{\circ}\right)$, temperate $\left(29^{\circ}\right.$ to $\left.54^{\circ}\right)$ and

91 subarctic-subantarctic (more than $55^{\circ}$ ) using the reported latitudes. Because of the coarse sand texture

92 of the soils, water is often a limiting resource in coastal dunes (Maun, 1994; Le Bagousse-Pinguet et

93 al., 2013). Therefore, we used mean annual precipitation (MAP) of each site as a proxy for

94 environmental severity. Based on the GPS coordinates listed in each paper, we extracted an estimate of

95 MAP for each study site from the meteorological forcing fields of the Global Land Data Assimilation

96 System, version 1 (GLDASv1). GLDAS is a global, high-resolution terrestrial modelling system that

97 incorporates satellite and ground-based observations in order to produce optimal fields of land surface

98 states and fluxes in near-real time (Rodell et al., 2004).

While MAP is one indicator of environmental severity, plant life at coastal dunes around the

100 world can be limited by a combination of factors such as nutrient limitation, salinity, and sand burial

101 (Maunn, 1994; Wilson \& Sykes, 1999). The complex nature of coastal limiting factors typically

102 justifies the use of integrative proxies for environmental severity such as plant biomass (Dullinger et

103 al., 2007; Maestre et al. 2009). For this reason, we also used the normalized difference vegetation index

104 (NDVI), a proxy for plant biomass (Paruelo et al., 1997; Doiron et al., 2013), as an integrative variable

105 of environmental severity at both local and regional scales. To estimate the NDVI of each site, we used

106 remote sensing techniques and two kinds of images with different resolutions: Advanced Spaceborn 
107 Thermal Emission and Reflection Radiometer (ASTER) images with $15 \mathrm{~m}$ resolution which provided a

108 local estimate of biomass vegetation; and Moderate Imaging Spectroradiometer (MODIS) images with

$109250 \mathrm{~m}$ resolution which also provided a regional estimation. For the NDVI based on ASTER images

110 (hereafter called local NDVI), we used the coordinates and description of the site (Reserve, National

111 Park, etc) and local vegetation provided by each study in order to place the study site within the image

112 as precisely as possible. Then, the archive of ASTER images available for each site were searched and

113 images were selected at the same time as the study implementation and also to minimize cloud cover.

114 For the NDVI based on MODIS images (hereafter called regional NDVI), mensal images were used

115 from 2001 to 2009. In order to synthesize this information for each site, the mensal NDVI was summed

116 annually to calculate the mean annual NDVI. All NDVI calculation was done using the software

117 ERDAS IMAGINE 2011 (Intergraph; Madison, AL, USA).

119 Meta Analysis

120 Suitable studies were grouped into eight different datasets according to the plant response variable

121 reported: density, survival, growth (which includes biomass and growth in height), richness (number of

122 species), reproductive output (which includes any quantitative measure of flower, fruit or seeds

123 production), occurrence, and emergence. Because we had two types of response variables, we used

124 different measures of effect size: the natural $\log$ of the response ratio $(\ln (\mathrm{RR}))$ for continuous response

125 variables (density, growth, richness and reproductive output), and the natural log odds ratio (ln (OR))

126 for binomial response variables (survival, occurrence and seed emergence) (Rosenberg, Rothstein \&

127 Gurevitch, 2013).

128 The natural $\log$ of the response ratio (ln (RR)) estimation, and its associated variance, was

129 calculated for each outcome using the mean, standard deviation (SD) and sample size (n) for control

130 (without neighbor) and treatment (with neighbor) (Rosenberg, Rothstein \& Gurevitch, 2013). Values of 
$131 \ln (\mathrm{RR})$ higher than 0 indicate a positive effect of the neighbor on the target performance (facilitation)

132 whilst values lower than 0 indicate a negative effect of the neighbor (competition). For categorical

133 responses, the natural $\log$ of the odds ratio $(\ln (\mathrm{OR}))$ and its associated variance for each outcome is

134 calculated using the number of success and failure occurrences for each treatment (Rosenberg,

135 Rothstein \& Gurevitch, 2013). In the case of survival for example, this measure denotes the number of

136 survival and dead plants with and without neighbors, positive values of $\ln (\mathrm{OR})$ also indicate

137 facilitation. In the few cases where survival data were reported as mean and SD, we first calculated

138 Hedges g, converted to Cohen d, and finally to the common index $\ln (\mathrm{OR})$ in order to combine all

139 survival outcomes in the same meta-analysis (Borenstein et al., 2009).

140 The effect of the neighbor was assessed for each one of the response variable datasets that

141 included in at least five independent studies (this was a conservative threshold to ensure general value

142 to the synthesis). We used a threshold to avoid potential biases from trends associated too few studies.

143 Bias-corrected bootstrap 95\% confidence intervals (CIs) were calculated for each overall effect size. If

144 the CI did not overlap zero, the effect was considered significant (Rosenberg, 2013). The Q-statistics

145 were used for each dataset in order to examine the heterogeneity among the effect sizes, and the

146 proportion of true variance in the effect sizes explained by each independent variable was estimated as

$147 \mathrm{R}^{2}$ (Borenstein et al., 2009). The significance of the model structure was tested by randomization tests

148 with 9999 iterations $(\alpha=0.05)$. The independent variables selected were i) geographic region (tropical,

149 temperate and subarctic-subantarctic regions), ii) neighbor life-form (i.e. tree, shrub, grass or forb); iii)

150 target life-form (i.e. tree, shrub, grass or forb); iv) target life stage; v) mean annual precipitation

151 (MAP); vi) local NDVI; and vii) regional NDVI.

152 Data were analyzed using mixed-effect models, that encompass both fixed and random effects,

153 with fixed differences among predictors (continuous or categorical covariates) and random variation 
154 among studies within levels of the predictor, as well sampling error within studies (Mergersen et al.,

155 2013). In the present context, the random variation among studies are more reasonable than fixed

156 variation because the complex interactions in ecology generally result in ecologically important

157 heterogeneity between studies (Pullin \& Stewart, 2006). Additionally, the use of mixed-effect models

158 (with random variation among studies instead of fixed variation) fits the goal of generalization usually

159 present in similar reviews (Borenstein et al., 2009). We tested publication bias calculating the

160 Rosenthal's fail number, specifically, that a fail-safe number larger than $5 n+10$ (where $n$ is the

161 number of outcomes) is a conservative critical value (Rosenthal, 1979). Funnel plots with Kendall's tau

162 rank correlation tests were also examined to explore potential publication bias. We used the $\mathrm{R}$

163 environment (version 3.1, R Core Team 2014) with the package metafor (Viechtbauer, 2010) for all

164 statistical analysis.

165

166 Results

167 Systematic Review

168 From 90 articles identified through database searching, a total of 32 articles met the selection criteria

169 for the systematic review (Supplemental Table S1). A PRISMA flow diagram was generated (Moher et

170 al., 2009) outlining the publication selection process (Fig. 1). These articles were published in 16

171 different journals between 1997 and 2013. These studies were performed in 13 countries, but a total of

$17231 \%$ of all studies were done on coastal dunes in the USA. With respect to diversity of climatic zones

173 examined, $63 \%$ of the studies were done in the temperate zone, $28 \%$ in the tropics, and $9 \%$ in the

174 arctic-subarctic zone. A total of 15 studies, i.e. $47 \%$, were observational and $8(25 \%)$ were

175 manipulative whilst 9 studies (28\%) used both approaches. A total of 362 independent outcomes were

176 extracted for the seven plant performance response variables. Density was the most frequent

177 representing $31 \%$ of the total, followed by survival (22\%), growth (18\%), reproductive output (12\%), 
178 richness $(8 \%)$, occurrence $(7 \%)$ and emergence (2\%). The earlier life stages for target plant species

179 were most represented in these studies (i.e., seedlings, saplings, and juveniles) with $43 \%$ of the total

180 number of measurements versus $20 \%$ of studies recording adults. Shrubs were the most common nurse-

181 plants examined representing $46 \%$ of the outcomes, followed by herb (36\%), tree (9\%), moss and

182 lichen (4\%) and a mix of life-forms used in $4 \%$ of the outcomes. The most common target life-forms

183 were herb (51\%), followed by mix of life-forms (24\%), shrub (19\%), tree (4\%), liana (1\%) and moss

$184(1 \%)$.

185

186

Meta-analysis

A total of 160 independent effect size estimates were suitable for the meta-analysis component

of this synthesis (Table 1). Density (Supplemental Table S2), growth (Supplemental Table S3) and

survival (Supplemental Table S4) datasets provided sufficient independent studies, i.e. at least 5 studies and 10 effect sizes (outcomes), to be considered in the meta-analysis (Table 1). There was no evidence of publication bias for density and growth (Kendall's tau $=0.14, \mathrm{P}=0.22$ for density; Kendall's tau= $0.06, \mathrm{P}=0.58$ for growth) and a limited indication of bias for survival (Kendall's tau $=-0.23, \mathrm{P}=0.04$ ).

193 The fail-safe numbers indicated that the results detected for density and survival could be driven by

194 limited or biased sets of publications available for synthesis (for density: critical threshold $=210$, fail-

195 safe number $=181$; for growth: critical threshold $=205$, fail-safe number $=468$, for survival: critical

196 threshold $=220$, fail-safe number $=40$ ).

Across all study outcomes, the presence of neighbor had no effect on the density of the target species examined (mean $\operatorname{lnRR}=0.38,95 \%$ confidence intervals: $-0.13-0.88$ ). However, the overall

199 heterogeneity test was significant indicating that the different study outcomes do not share a common

200 effect and explanatory variables may explain the observed variability among study outcomes $(\mathrm{Q}=644$;

$201 \mathrm{df}=39, \mathrm{P}<0.0001)$. However, the variability in effect sizes for plant density were not explained by any 
202 of the factors we considered (Table 2). The presence of neighbors had a positive effect on the growth

203 of the target species (Fig. 2A). The overall heterogeneity test was significant $(\mathrm{Q}=186 ; \mathrm{df}=38, \mathrm{P}<$

2040.0001 ) but only geographic region factor was a significant predictor of the variability amongst

205 outcomes (Table 2). In the temperate and subarctic regions, there is no evidence of neighboring effect

206 on target growth (Fig. 2A). In the tropics, the presence of neighbor increased the growth of target

207 species (Fig. 2A). The survival of target plants was not significant affected by the presence of

208 neighbors (Fig. 2B). The test of within-study heterogeneity was significant $(\mathrm{Q}=178 ; \mathrm{df}=41, \mathrm{P}<0.001)$,

209 but again only geographic region was a significant explanatory factor (Table 2). Target plant survival

210 in tropical regions was increased by neighbours but not in the coastal dunes from temperate regions

211 (Fig. 2B).

212

\section{Discussion}

214 Empirical studies support the hypothesis that facilitation between plants is an important ecological

215 process in severe environments (Brooker et al., 2008) including as demonstrated herein coastal dunes.

216 The first goal of the systematic review was to highlight general research gaps in the plant facilitation

217 research in coastal dunes. We found a clear concentration of dune facilitation studies in temperate

218 dunes indicating that to assess the impact of climate differences and gradients on facilitation between

219 plants future studies need to be done in other dune systems such as the tropics. The systematic review

220 also identified a predominance of observational studies over experimental studies, and this is

221 unfortunate in many respects given that the former is a weaker form of inductive inference. The second

222 goal of this study was to examine the importance of factors quantitatively and contrast different scales

223 of drivers on interaction strengths. The response variables measured in facilitation studies were an

224 important determinant of the factors determining the strength of interactions. For the three response

225 variables considered (density, growth, and survival), we found significant evidence for the importance 
226 of geographic region in determining the magnitude of facilitation, but no evidence for the effects of

227 climatic and local factors within a region such as life form and life stage of the interacting species.

228 Collectively, this indicates that facilitation is important in coastal dunes and that its relative intensity is

229 best described by the regional context.

230 As highlighted previously, the clear concentration of dune facilitation studies in temperate

231 dunes suggests that we need to expand the scope of coastal dune interaction studies to other geographic

232 regions. This is important for a number of reasons. Macroecological synthesis is an important, novel,

233 and dominant source of theory validation in community ecology (Keith et al., 2012). Alpine and semi-

234 arid syntheses (Maestre, Valladares \& Reynolds, 2005; Arredondo-Núnez, Badano \& Bustamante,

235 2009) and large-scale integrated experiments (Fraser et al., 2013) are a powerful means to test global

236 issues including the importance of small-scale processes (Paine, 2010) such as interactions.

237 Considering that coastal dunes are subject to significant global change effects (van der Meulen, Witter

$238 \&$ Ritchie, 1991), understanding how plant interactions vary between geographic regions increases

239 predictive ecology on important issues such as climate change effects on plant community structure

240 globally (Michalet et al., 2014). As highlighted by Hesp (2004), even though few comparative studies

241 have been carried out, differences in factors such as species, adaptative strategies and rates of plants

242 growth indicate that ecological processes may be distinct between tropical and temperate dunes in

243 many systems.

244 Another major limitation identified by the systematic review was the predominance of

245 observational studies over experimental studies. Observational studies included spatial association

246 analyses among species (McIntire \& Fajardo 2009; Cushman, Waller \& Hoak, 2010; Castanho,

247 Oliveira \& Prado 2012). Although positive associations provide evidence of facilitation, this

248 associational pattern does not exclude alternative explanations such as shared physical microhabitats

249 requirements and the tendency of some plants to act as foci for seed deposition (Callaway 1995). 
250 Alternatively, experimental manipulations provide a causal form of verification for plant facilitation

251 because the mechanistic pathways can be identified (Callaway 2007). Consequently, we also

252 recommend that coastal dunes be studied more comprehensively using manipulative approaches or a

253 combination of observational and experimental methodologies to decouple direct from indirect effects

254 (Kunstler et al., 2006), identify mechanisms (Shumway, 2000; Maestre, Bautista \& Cortina, 2003;

255 Cushman, Lortie \& Christian, 2011), and examine the importance of local variation (Lu et al., 2011;

256 McIntire \& Fajardo, 2014). The extent that facilitation or plant interactions in general can be used to

257 manage or restore highly impacted/stressed systems such as coastal dunes is generally best examined 258 through manipulation.

The quantitative examination of plant facilitation magnitude across studies, i.e. the meta-

260 analyses, showed that the factors influencing the occurrence and magnitude of facilitation in coastal

261 dunes depended on the response variable measured. Whilst geographical region influenced the

262 magnitude of facilitation for plant growth and survival, no effect of region was observed on

263 interactions regarding plant density (Table 2). This result supports the general findings of another

264 meta-analysis on facilitation for arid and semi-arid environments that concluded that the effect of

265 abiotic stress on the outcome of interactions depended on the plant response (Maestre, Valladares \&

266 Reynolds, 2005). In order to explain this difference between response variables, we need to better

267 understand how the neighbor presence changes the conditions and resources in its neighborhood and

268 how it affects the distinct species-specific responses (Michalet et al. 2014). Therefore, to better

269 understand the factors affecting the magnitude of positive interactions, we must investigate the

270 mechanisms behind facilitative interactions in coastal dunes and importantly also record multiple target

271 responses to neighbors (Hastwell \& Facelli, 2003; Brooker et al., 2008). This is rarely done in a single

272 study (but see for instance Rudgers \& Maron, 2003; Cushman, Lortie \& Christian, 2011) but is

273 nonetheless an important avenue of research that will benefit assessment of restoration efforts. 
Growth and survival trends suggest that geographic region mediates the presence of facilitation

275

276

277

278

279

280

281

282

283

284

285

286

287

288

289

290

291

292

293

294

295

296

more broadly in coastal dune systems. This is a very novel finding (Thebault et al. 2014). Altogether, these results showed that the presence of a neighbor was positive for plant survival and growth in the tropical region, whereas in the temperate and subarctic regions, the effects were neutral for both plant response variables. The environmental severity is relative to the stress tolerance and resource use adaptations of the species within a system (Lortie, 2010). The species composition and predominant life-forms differ between tropical and temperate dunes (Hesp, 2004). Therefore, the observed result can be the product of different sets of traits associated with the species in each region respectively, and consequently, distinct sensitivities to the changes in conditions and resources generated by neighbor presence in the tropical and temperate dunes. However, the limited number of tropical studies indicates that we need to be cautious in the generalization of this alternative hypothesis at this junction. In the present synthesis, we focused on only facilitation studies to test hypothesis related to the magnitude of this interaction, although competition and facilitation are of course both subsets of plant-plant interactions. To explore and contrast the relative importance of competition and facilitation, primary studies in coastal dunes must now test them directly and concurrently and the scope of a synthesis must be expanded including also plant competition studies.

The capacity for regional drivers of change to mediate positive, local interactions is a novel and important challenge to traditional community ecology and suggests that studies must also now consider the regional context in studying plant-plant interactions even at relatively fine scales in these systems. From a restoration and management perspective, this also suggests that best practices in using facilitation to reduce potential anthropogenic or disturbance effects may need to be tested and/or applied via different mechanistic pathways depending on the importance of regional drivers on productivity gradients and specific local limitations to key target plant species. 
The use of remote sensing data together with meta-analytical techniques could be a powerful tool

298 to explore the importance of climatic and environmental covariates (usually not provided by primary

299 studies) driving ecological processes. In the present study we did not find an effect of NDVI and MAP

300 on the variability of plant interaction in coastal dunes. One possible explanation for the failure to detect

301 a significant effect of the remote sensing covariates and the other local covariates also tested (plant life-

302 form and life-stage) is the highly variable nature of ecological data together with the small number of

303 primary studies available to construct a big picture. However, as we accumulate primary data testing

304 plant facilitation in coastal dunes, we should be able to drawn synthesis with more definitive

305 conclusions about the factors driving facilitation intensity. 


\section{References}

308 Armas C, Pugnaire FI. 2009. Ontogenetic shifts in interactions of two dominant shrub species in a semi-arid coastal sand dune system. Journal of Vegetation Science 20: 535-546.

Arredondo-Núnez A, Badano EI, Bustamante RO. 2009. How beneficial are nurse plants? A metaanalysis of the effects of cushion plants on high-Andean plant communities. Community Ecology 10: 1-6. plant. Oikos 115: 369-385. Evolution 9: 191-193.

Badano EI, Jones CG, Cavieres LA, Wright JP. 2006. Assessing impacts of ecosystem engineers on community organization: a general approach illustrated by affects of a high-Andean cushion Bertness MD, Callaway R. 1994. Positive interactions in communities. Trends in Ecology and

Bertness MD, Hacker SD. 1994. Physical stress and positive associations among marsh plants.

$$
\text { American Naturalist 144: 363-372. }
$$

Bertness MD, Leonard GH. 1997. The role of positive interactions in communities: lessons from intertidal habitats. Ecology 78: 1976-1989.

Borenstein M, Hedges LV, Higgins JPT, Rothstein HR. 2009. Introduction to meta-analysis. John Wiley \& Sons.

Brooker RW, Callaghan TV. 1998. The balance between positive and negative plant interactions and its relationship to environmental gradients: a model. Oikos 81: 196-207.

Brooker RW, Maestre FT, Callaway R, Lortie CL, Cavieres LA, Kunstler G, Liancourt P, Tielbörger K, Travis JMJ, Anthelme F, Armas C, Coll L, Corcket E, Delzon S, Forey E, Kikvidge Z, Olofsson J, Pugnaire F, Quiroz CL, Saccone P, Schiffers K, Seifan M, Touzard B, Michalet R. 2008. Facilitation in plant communities: the past, the present, and the future. Journal of Ecology 96: $18-34$. 
331 Brooker RW, Callaway RM, Cavieres LA, Kikvidze Z, Lortie CJ, Michalet R, Pugnaire FI, ValienteBanuet A, Whitham TG. 2009. Don't diss integration: a comment on Ricklefs's disintegrating communities. American Naturalist 174: 919-927.

334 Callaway RM. 1995. Positive interactions between plants. The Botanical Review 61: 306-349.

335 Callaway RM. 2007. Positive interactions and interdependence in plant communities. Springer.

336 Castanho CT, Oliveira AA, Prado PI. 2012. The importance of plant life form on spatial associations along a subtropical coastal dune gradient. Journal of Vegetation Science 23: 952-961.

Castanho CT, Prado PI. 2014. Benefit of shading by nurse plant does not change along a stress gradient in a coastal dune. Plos One 9(8): e105082.

Cavieres LA, Brooker RW, Butterfield BJ, Cook BJ, Kikvidze Z, Lortie CJ, Michalet R, Pugnaire FI, Schöb C, Xiao S, Anthelme F, Björk RG, Dickinson KJM, Cranston BH, Gavilán R, Gutiérrez-

RM. 2014. Facilitative plant interactions and climate simultaneously drive alpine plant diversity. Ecology Letters 17: 193-202.

Cushman JH, Waller JC, Hoak DR. 2010. Shrubs as ecosystem engineers in a coastal dune: influences on plant populations, communities and ecosystems. Journal of Vegetation Science 21: 821-831.

Cushman JH, Lortie CJ, Christian CE. 2011. Native herbivores and plant facilitation mediate the performance and distribution of an invasive exotic grass. Journal of Ecology 99: 524-531.

Doiron M, Legagneux P, Gauthier G, Lévesque E. 2013. Broad-scale satellite Normalized Difference Vegetation Index data predict plant biomass and peak date of nitrogen concentration in Arctic tundra vegetation. Applied Vegetation Science 16: 343-351.

Dullinger S, Kleinbauer I, Pauli H, Gottfried M, Brooker R, Nagy L, Theurillat JP, Holten JI, Abdaladze O, Benito JL, Borel JL, Coldea G, Ghosn D, Kanka R, Merzouki A, Klettner C, 
Mosieev P, Molau U, Reiter K, Rossi G, Stanisci A, Tomaselli M, Unterlugauer P, Vittoz P, 2007, Garbher R. Weak and variable relationships between environmental severity and smallscale co-occurrence in alpine plant communities. Journal of Ecology 95: 1284-1295.

Flores J, Jurado E. 2003. Are nurse-protégé interactions more common among plants from arid environments? Journal of Vegetation Science 14: 911-916.

Franco AC, Nobel PS. 1989. Effect of nurse plants on the microhabitat and growth of cacti. Journal of Ecology 77: 870-886.

Fraser LH, Henry HAL, Carlyle CN, White SR, Beierkuhnlein C, Cahill Jr JF, Casper BB, Cleland E, Collins SL, Dukes JS, Knapp AK, Lind E, Long R, LuoY, Reich PB, Smith MD, Sternberg M, Turkington R. 2013. Coordinated distributed experiments: an emerging toll for testing global hypotheses in ecology and environmental science. Frontiers in Ecology and the Environment 11: 147-155.

Forey E, Lortie CJ, Michalet R. 2009. Spatial patterns of association at local and regional scales in coastal sand dunes communities. Journal of Vegetation Science 20: 916-925.

Gómez-Aparicio L. 2009. The role of plant interactions in the restoration of degraded ecosystems: a meta-analysis across life-forms and ecosystems. Journal of Ecology 97:1202-1214

Hastwell GT, Facelli JM. 2003. Differing effects of shade-induced facilitation on growth and survival during the establishment of a chenopod shrub. Journal of Ecology 91: 941-950.

He Q, Bertness MD, Altieri AH. 2013. Global shifts towards positive species interactions with increasing environmental stress. Ecology Letters 16: 695-706.

Hesp PA. 2004. Coastal dunes in the tropics and temperate regions: location, formation, morphology and vegetation process. In: Martínez ML, Psuty NP, eds. Coastal dunes - ecology and conservation. Springer-Verlag, 29-49.

Jones RB. 1998. TechDig. Version 2.0d. Mundelein. 
379 Keith SA, Webb TJ, Böhning-Gaese K, Connolly SR, Dulvy NK, Eigenbrod F, Jones KE, Price T, 380 Redding DW, Owens IPF, Isaac NJB. 2012. What is macroecology? Biology Letters 8: 904-906.

381 Kunstler G, Thomas C, Monique B, Jacques L. 2006. Indirect facilitation and competition in tree 382 species colonization of sub-mediterranean grasslands. Journal of Vegetation Science 17: 379$383 \quad 388$.

384 Le Bagousse-Pinguet Y, Forey E, Touzard B, Michalet R. 2013. Disentangling the effects of water and 385 nutrients for studying the outcome of plant interactions in sand dune ecosystems. Journal of Vegetation Science 24: 375-383.

Lithgow D, Martínez ML, Gallego-Fernández JB, Hesp PA, Flores P, Gachuz S, Rodríguez-Revelo N, Jiménez-Orocio O, Mendoza-González G, Álvarez-Molina LL. 2013. Linking restoration ecology with coastal dune restoration. Geomorphology 199: 214-224.

\section{2}

Lortie CJ. 2010. Synthetic analysis of the stress-gradient hypothesis. In: Pugnaire FI, ed. Positive plant interactions and community dynamics. CRC Press, 125-147.

Lortie CJ, Brooker RW, Choler P, Kikvidze Z, Michalet R, Pugnaire FI, Callaway RM. 2004. Rethinking plant community theory. Oikos 107: 433-438.

Lu J, Jiang L, Yu L, Sun Q. 2011. Local factors determine plant community structure on closely neighbored islands. Plos One 6: e19762.

Maestre FT, Bautista S, Cortina J. 2003. Positive, negative and net effects in grass-shrub interactions in Mediterranean semiarid grasslands. Ecology 84: 3186-3197.

Maestre FT, Martínez I, Escolar C, Escudero A. 2009. On the relationship between abiotic stress and co-occurrence patterns: as assessment at the community level using soil lichen communities and multiple stress gradients. Oikos 118: 1015-1022. 
401 Maestre FT, Valladares F, Reynolds JF. 2005. Is the change of plant-plant interactions with abiotic stress predictable? A meta-analysis of field results in arid environments. Journal of Ecology 93: 748-757.

404

405

406

407

408

409

410

Martínez ML. 2003. Facilitation of seedling establishment by an endemic shrub in tropical coastal sand dunes. Plant Ecology 168: 333-345.

Martínez ML, García-Franco JG. 2004. Plant-plant interactions in coastal dunes. In: Martínez ML \& Psuty NP, eds. Coastal dunes: ecology and conservation. Springer, 205-220.

Maun MA. 1994. Adaptations enhancing survival and establishment of seedlings on coastal dune systems. Vegetatio 111: 59-70.

McIntire EJB, Fajardo A. 2009. Beyond description: the active and effective way to infer processes from spatial patterns. Ecology 90: 46-56.

McIntire EJB, Fajardo A. 2014. Facilitation as a ubiquitous driver of biodiversity. New Phytologist 201: 403-416.

Mengersen K, Schmid CH, Jennions MD, Gurevitch J. 2013. Statistical models and approaches to inference. In: Koricheva J, Gurevitch J, Mengersen K, eds. Handbook of meta-analysis in ecology and evolution. Princenton University Press, 108-124.

Michalet R, Schöb C, Lortie CL, Brooker RW, Callaway RM. 2014. Partitioning net interactions among plants along altitudinal gradients to study community responses to climate change. Functional Ecology 28: 75-86.

Miriti MN. 2006. Ontogenetic shift from facilitation to competition in a desert shrub. Journal of Ecology 94: 973-979.

Moher D, Liberati A, Tetzlaff J, Altman DG, PRISMA Group. 2009. Preferred reporting items for systematic reviews and meta-analyses: the PRISMA statement. Plos Medicine 6 (7): e1000097. 
424 O’Halloran LR, Borer ET, Seabloom EW, MacDougall AS, Cleland EE, McCulley RL, Hobbie S, Harpole WS, DeCrappeo NM, Chu C, Bakker JD, Davies KF, Du G, Firn J, Hagenah N, Hofmockel KS, Knops JMH, Li W, Melbourne BA, Morgan JW, Orrock JL, Prober SM, Stevens CJ. 2013. Regional contingencies in the celationship between aboveground biomass and litter in the world's grasslands. Plos One 8: e54988.

Paine R. 2010. Macroecology: does it ignore or can it encourage further syntheses based on spatially experimental manipulations? American Naturalist 176: 385-393.

Paruelo JM, Epstein HE, Lauenroth WK, Burke I .1997. ANPP estimates from NDVI for the central grassland region of the United States. Ecology 78: 953-958.

Powers JS, Montgomery RA, Adair EC, Brearley FQ, DeWalt SJ, Castanho CT, Chave J, Deinert E, Jörg U. Ganzhorn JU, Gilbert ME, González-Iturbe JA, Bunyavejchewin S, Grau HR, Harms KE, Hiremath A, Iriarte-Vivar S, Manzane E, Oliveira AA, Poorter L, Ramanamanjato J, Salk C, Varela A, Weiblen GD, Lerdau MT. 2009. Decomposition in tropical forests: a pan-tropical study of the effects of litter type, litter placement and mesofaunal exclusion across a precipitation gradient. Journal of Ecology 97: 801-811.

Pullin AS, Stewart GB. 2006. Guidelines for systematic review in conservation and environmental management. Conservation Biology 20: 1647-1656.

R Core Team. 2014. R: A language and environment for statistical computing. R Foundation for Statistical Computing, Vienna, Austria. URL http://www.R-project.org/.

Ricklefs RE. 2004. A comprehensive framework for global patterns in biodiversity. Ecology Letters 7: $1-15$.

Rodell M, Houser PR, Jambor U, Gottschalck J, Mitchell K, Meng CJ, Arsenault K, Cosgrove B, Radakovich J, Bosilovich M, Entin JK, Walker JP, Lohmann D, Toll D. 2004. The global land data assimilation system. Bulletin of American Meteorogical Society 85: 381-394. 
448 Rosenberg MS. 2013. Moment and least-square based approaches to meta-analytic inference. In:

449 Koricheva J, Gurevitch J, Mengersen K, eds. Handbook of meta-analysis in ecology and 450 evolution. Princenton University Press, 108-124.

451 Rosenberg MS, Rothstein HR, Gurevitch J. 2013. Effect sizes: conventional choices and calculations.

452 In: Koricheva J, Gurevitch J, Mengersen K, eds. Handbook of meta-analysis in ecology and 453 evolution. Princenton University Press, 61-71.

454 Rosenthal R. 1979. The "file drawer problem" and tolerance for null results. Psychological Bulletin 86: $455 \quad 638-641$.

456 Rudgers JA, Maron JL. 2003. Facilitation between coastal dune shrubs: a non-nitrogen fixing shrub 457 facilitates establishment of a nitrogen-fixer. Oikos 102: 75-84.

458 Scarano FR. 2002. Structure, function and floristic relationships of plant communities in stressful 459 habitats marginal to the Brazilian Atlantic rainforest. Annals of Botany 90: 517-524.

460 Shumway SW. 2000. Facilitative effects of a sand dune shrub on species growing beneath the shrub $461 \quad$ canopy. Oecologia 124: 138-148.

462 Soliveres S, Maestre FT, Bowker MA, Torices R, Quero JL, García-Gomez M, Cabrera O, Cea AP, 463 Coaguila D., David EJ, Espinosa CI, Hemmings F, Monerris JJ, Tighe M, Delgado-Baquerizo M, 464 Escolar C, García-Palacios P, Gozalo B, Ochoa V, Blones J, Derak M, Ghiloufi W, Gutiérrez JR, 465 Hernández RM, Noumi Z .2014. Functional traits determine plant co-occurrence more than 466 environment or evolutionary relatedness in global drylands. Perscpectives in Plant Ecology, $467 \quad$ Evolution and Systematics 16: 164-173.

468 Takimoto G. 2011. Local-regional richness relationships and alternative stable states in 469 metacommunities with local facilitation. Theoretical Ecology 4: 385-395.

470 Thebault A, Mariotte P, Lortie JC, MacDougall AS. 2014. Land management trumps the effects of 471 climate change and elevated CO2 on grassland functioning. Journal of Ecology 102: 896-904. 
472 Van der Meulen F, Witter JV, Ritchie W. 1991. Impact of climatic change on coastal dune landscapes 473 of Europe. Landscape Ecology 6: 5-6.

474 Viechtbauer W. 2010. Conducting meta-analysis in R with the metafor package. Journal of Statistical $475 \quad$ Software 36: 1-48.

476 Wilson JB, Sykes MT. 1999. Is zonation on coastal sand dunes determined primarily by sand burial or 477 by salt spray? A test in New Zealand dunes. Ecology Letters 2: 233-236. 
1

Prisma flow diagram.

Figure 1. Prisma flow diagram depicting the seach protocol and workflow in determining the effective population of studies for systematic review and meta-analysis.

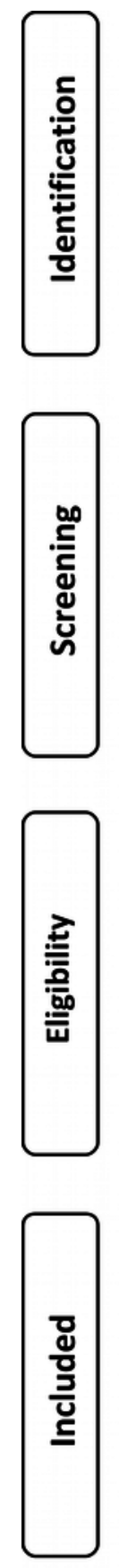

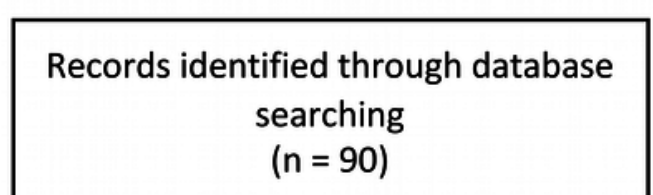

Records after duplicates removed $(n=90)$
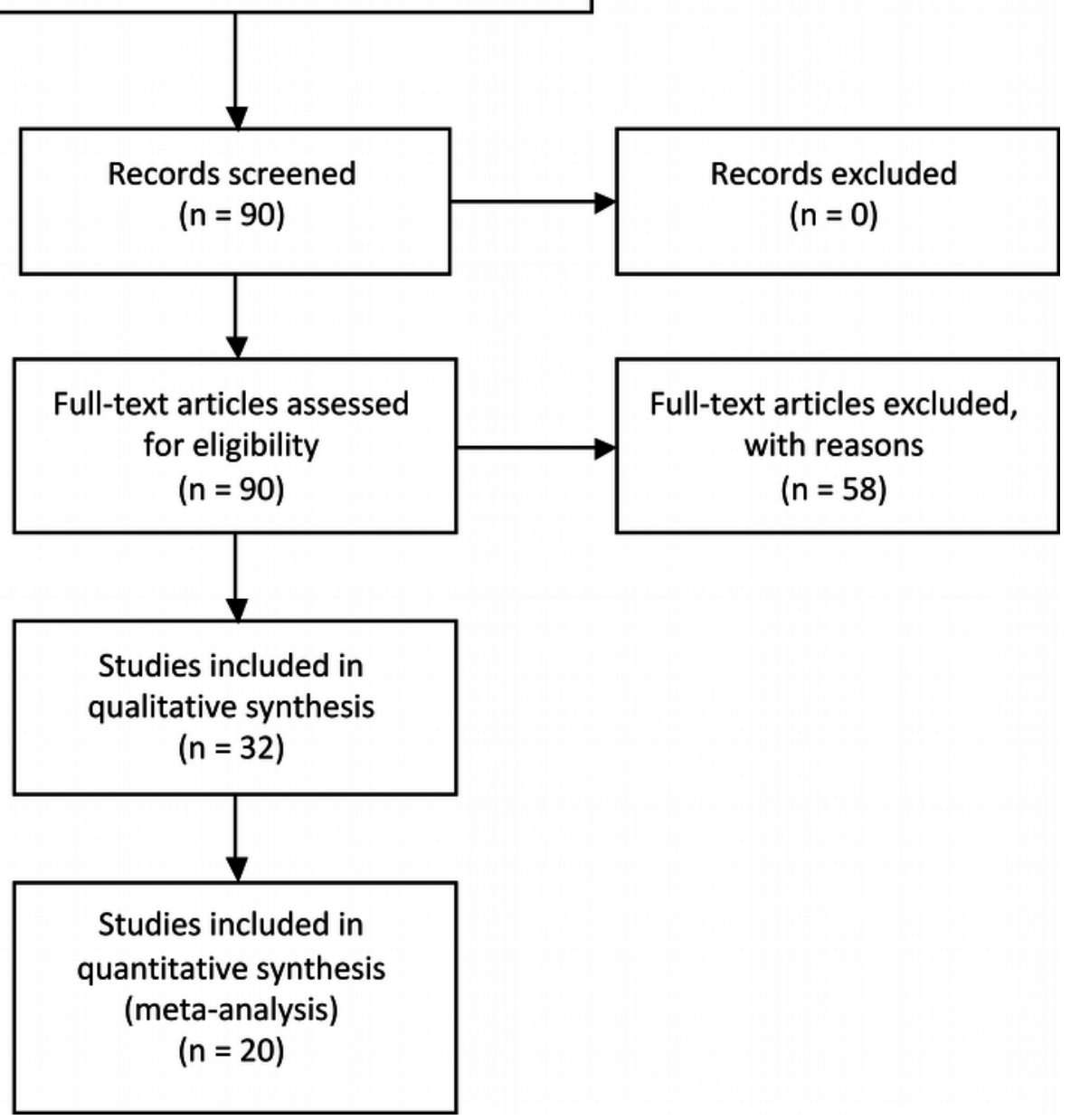
Table $\mathbf{1}$ (on next page)

Meta-analysis studies.

Table 1. The total number of suitable independent cases for meta-analysis (outcomes) and the respective total publications for each plant response variable studied in coastal dune systems globally. The WoS search tool was used to populate the list of studies used. 


\section{PeerJ Reviewing Manuscript}

\begin{tabular}{lll}
\hline PERFOMANCE & N CASES & N PUBLICATIONS \\
\hline Density & 40 & 10 \\
Growth & 39 & 10 \\
Survival & 42 & 8 \\
Richness & 17 & 4 \\
Reproductive output & 10 & 4 \\
Emergence & 4 & 2 \\
Occurrence & 8 & 2 \\
\hline
\end{tabular}


Table 2 (on next page)

Summary of meta-analyses results.

Table 2. Summary of the random effect models used to examine the key factors on plant neighbor effects for plant density, growth, and survival in coastal dune systems. DF= degrees of freedom; $R^{2}=$ proportion of the true variation explained by the independent variable; Slope $=$ only applicable for continuous predictors. 
PeerJ Reviewing Manuscript

\begin{tabular}{llllll}
\hline & EFFECT & DF & $\mathbf{R}^{2}(\boldsymbol{\%})$ & SLOPE & $\mathbf{P}$ \\
\hline \multirow{5}{*}{ Density } & Geographic region & 2,37 & 0.7 & -------- & 0.33 \\
& MAP & 1,38 & 0.0 & -0.0003 & 0.67 \\
& NDVI - regional & 1,38 & 0.0 & -0.124 & 0.49 \\
& NDVI - local & 1,27 & 0.0 & 1.070 & 0.54 \\
& Neighbor life-form & 2,37 & 0.0 & -------- & 0.98 \\
& Target life-form & 3,36 & 0.0 & -------- & 0.88 \\
& Target life stage & 2,37 & 0.0 & -------- & 0.69 \\
\hline \multirow{5}{*}{ Growth } & Geographic region & 2,36 & 20.0 & -------- & $\mathbf{0 . 0 3}$ \\
& MAP & 1,37 & 0.0 & 0.001 & 0.13 \\
& NDVI - regional & 1,36 & 0.0 & -0.030 & 0.70 \\
& NDVI - local & 1,15 & 0.0 & -0.136 & 0.95 \\
& Neighbor life-form & 1,37 & 0.0 & -------- & 0.62 \\
& Target life-form & 1,37 & 0.0 & -------- & 0.40 \\
& Target life stage & 2,36 & 17.5 & -------- & 0.08 \\
\hline \multirow{5}{*}{ Survival } & Geographic region & 1,40 & 17.1 & --------- & $\mathbf{0 . 0 3}$ \\
& MAP & 1,40 & 0.0 & -0.001 & 0.40 \\
& NDVI - regional & 1,40 & 0.0 & -0.113 & 0.29 \\
& NDVI - local & 1,28 & 0.0 & -1.646 & 0.30 \\
& Neighbor life-form & 2,39 & 0.0 & --------- & 0.15 \\
& Target life-form & 2,39 & 0.0 & -------- & 0.36 \\
& Target life stage & 1,34 & 9.2 & -------- & 0.19 \\
\hline
\end{tabular}


2

Mean effect sizes by geographical region, and the overall effect for plant growth and survival, in coastal dune systems.

Figure 2. Mean effect sizes by geographical region, and the overall effect for A) plant growth and B) plant survival, in coastal dune systems. Error bars are bias-corrected bootstrap 95\% confidence intervals. The number of independent cases (outcomes) is shown in parentheses. Across all study cases, the presence of neighbor had a positive effect on overall growth but no effect on survival of the target species (given that confidence intervals that do overlap zero). Geographic region explained a portion of the variability among study cases ( $20 \%$ of target growth and $17 \%$ of survival). Although the small number of cases in the tropical region, neighboring plants increases the growth and survival of target plants in the tropics (confidence interval do not overlap zero), while no effect was observed in the temperate region and subartic (the last just in the case of growth).

A) Growth

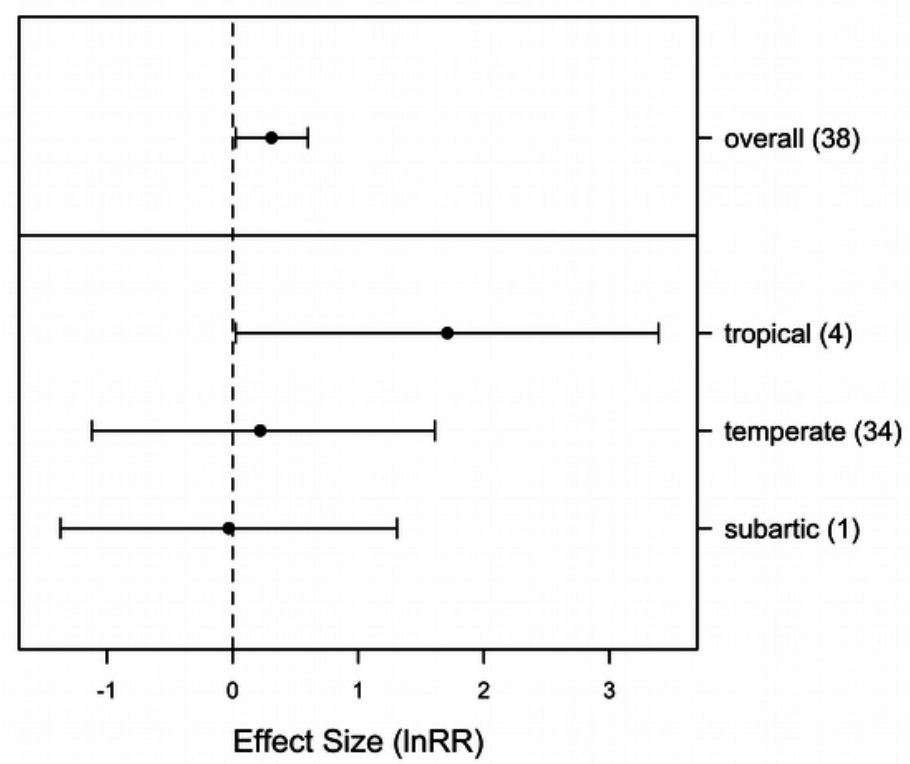

B) Survival

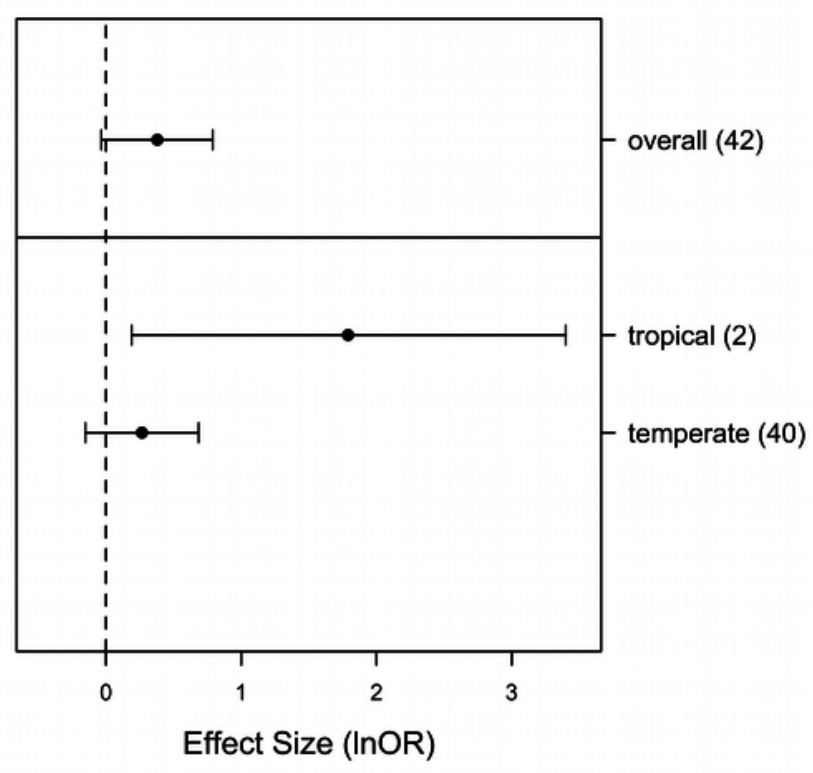

